\title{
Uncertainties of ground-based microwave radiometer retrievals in zenith and off-zenith observations under snow conditions
}

\author{
Wengang Zhang ${ }^{1}$, Guirong $\mathrm{Xu}^{1}$, Yuanyuan $\mathrm{Liu}^{2}$, Guopao $\mathrm{Yan}^{3}$, Dejun $\mathrm{Li}^{4}$, and Shengbo Wang ${ }^{5}$ \\ ${ }^{1}$ Hubei Key Laboratory for Heavy Rain Monitoring and Warning Research, Institute of Heavy Rain, \\ China Meteorological Administration, Wuhan, China \\ ${ }^{2}$ Hubei Meteorological Information and Technological Support Center, Wuhan, China \\ ${ }^{3}$ Wuhan Meteorological Bureau of Hubei Province, Wuhan, China \\ ${ }^{4}$ Hubei Meteorological Service Center, Wuhan, China \\ ${ }^{5}$ Mewbourne School of Petroleum \& Geological Engineering, University of Oklahoma, Norman, USA \\ Correspondence to: Guirong Xu (grxu@whihr.com.cn)
}

Received: 27 July 2016 - Published in Atmos. Meas. Tech. Discuss.: 15 August 2016

Revised: 5 December 2016 - Accepted: 13 December 2016 - Published: 11 January 2017

\begin{abstract}
This paper is to investigate the uncertainties of microwave radiometer (MWR) retrievals in snow conditions and also explore the discrepancies of MWR retrievals in zenith and off-zenith observations. The MWR retrievals were averaged in a \pm 15 min period centered at sounding times of 00:00 and 12:00 UTC and compared with radiosonde observations (RAOBs). In general, the MWR retrievals have a better correlation with RAOB profiles in off-zenith observations than in zenith observations, and the biases (MWR observations minus RAOBs) and root mean square errors (RMSEs) between MWR and RAOB are also clearly reduced in off-zenith observations. The biases of temperature, relative humidity, and vapor density decrease from $4.6 \mathrm{~K}$, $9 \%$, and $1.43 \mathrm{~g} \mathrm{~m}^{-3}$ in zenith observations to $-0.6 \mathrm{~K},-2 \%$, and $0.10 \mathrm{~g} \mathrm{~m}^{-3}$ in off-zenith observations, respectively. The discrepancies between MWR retrievals and RAOB profiles by altitude present the same situation. Cases studies show that the impact of snow on accuracies of MWR retrievals is more serious in heavy snowfall than in light snowfall, but off-zenith observation can mitigate the impact of snowfall. The MWR measurements become less accurate in snowfall mainly due to the retrieval algorithm, which does not consider the effect of snow, and the accumulated snow on the top of the radome increases the signal noise of MWR measurements. As the snowfall drops away by gravity on the sides of the radome, the off-zenith observations are more representative of the atmospheric conditions for RAOBs.
\end{abstract}

\section{Introduction}

Atmospheric profiles of temperature, relative humidity, and vapor density can be retrieved from ground-based microwave radiometer (MWR) measurements (Sánchez et al., 2013; Ware et al., 2013). These profiles are available nearly continuously and are extensively utilized in the forecasting and analysis of intense convective weather; also they have been assimilated into numerical weather prediction models (Marzano et al., 2005; Knupp et al., 2009; Löhnert and Maier, 2012; Madhulatha et al., 2013). The instability indices calculated from the MWR-retrieved thermodynamic atmospheric profiles are also employed in operational meteorology (Chan and Hon, 2010; Cimini et al., 2015; Leena et al., 2015). With the purpose of improving the MWR measurement accuracy, some procedures and methods are performed. A method based on linear regression is employed to reduce the discrepancy between the MWR retrievals and the radiosonde observation (RAOB) profiles (Sánchez et al., 2013). However, since the radiative transfer model used in the MWR does not consider the impact of precipitation on the MWR brightness temperature measurements, the MWR retrievals become less accurate under precipitation conditions (Ware et al., 2004; $\mathrm{Xu}$ et al., 2014). To minimize the influence of liquid water on MWR measurements, the MWR is equipped with an inverted "U"-shaped hydrophobic radome and a special blower system, which can sweep water beads and snow away from the radome (Chan, 2009). Recently, off-zenith observation has been applied in MWR observations, and off-zenith retrievals 
provide higher accuracy during precipitation by minimizing the effect of liquid water on the radiometer radome (Cimini et al., 2011, 2015; Ware et al., 2013; Xu et al., 2014).

Snow, as a special type of precipitation, has distinct scattering characteristics in the microwave region. Some methods are explored to investigate these characteristics and discuss their utilization in the snow measurements (Matrosov et al., 2008; Löhnert et al., 2011; Xie et al., 2012). The scattering signal of snow is highly dependent on the assumption of snow shape and snow size distribution (SSD), especially for large-sized parameters (Kneifel et al., 2010). Some studies have demonstrated that snowfall can significantly reduce the measurement accuracy of MWR (Knupp et al., 2009; Cimini et al., 2011; Ware et al., 2013). However, few studies are reported on the improvements of MWR measurement accuracies in snow conditions. Moreover, in contrast with rain, snow usually freezes on the top of the radome, and it is not easily blown away from the radome by the blower system attached on the MWR. Since MWR retrieval accuracies generally are better in off-zenith observations than in zenith observations under precipitation conditions (Xu et al., 2014) and snow does not easily accumulate on the sides of a radome, we attempt to employ off-zenith observation to improve the MWR measurement accuracies during snowfall.

This paper is organized as follows: Sect. 2 will briefly describe the data and methodology employed in this study; Sect. 3 compares the MWR-retrieved atmospheric profiles of temperature, relative humidity, and vapor density with RAOB profiles obtained at Wuhan station and then discusses the accuracies of MWR retrievals under snow conditions and the effect of off-zenith observation on it; and Sect. 4 gives some conclusions.

\section{Data and methodology}

The data used in this study are collected in the Wuhan operational station $\left(30.6^{\circ} \mathrm{N}, 114.1^{\circ} \mathrm{E}\right.$, and $23 \mathrm{~m}$ a.s.l.), including RAOB data, meteorological observation data, disdrometer data, and MWR data. The distances between RAOB launching station, disdrometer, MWR, and meteorological sensors are all less than $30 \mathrm{~m}$, but the distance between sounding profile and MWR retrieval at high altitude may become larger due to radiosonde drifting. RAOB data are the operational data, which are obtained at 00:00 and 12:00 UTC every day. The profiles of temperature and relative humidity are obtained by the Chinese GTS1-2 digital radiosonde at a high vertical resolution of $10 \mathrm{~m}$, and the profiles of vapor density can be calculated from them. The meteorological observation data are used to confirm the snowfall cases. The disdrometer located at the Wuhan site is a Thies Clima disdrometer manufactured in Germany. It is well suited for the measurement and detection of different types and intensity of precipitation with temporal resolution of $1 \mathrm{~min}$. With the aid of the disdrometer, the particles with sizes from 0.16 to
$8 \mathrm{~mm}$ and speed from 0.2 to $20 \mathrm{~m} \mathrm{~s}^{-1}$ can be measured. The range of precipitation intensity measured by disdrometer is from 0.005 to $250 \mathrm{~mm} \mathrm{~h}^{-1}$. Unfortunately, this instrument is not equipped with sensors that can measure the ambient temperature, relative humidity, wind speed, and direction. The MWR data used in this paper are provided by a MP-3000A unit manufactured by Radiometrics Corporation in the USA, observing at two elevation angles (zenith and $15^{\circ}$ elevation). The MWR data have a high temporal resolution of $\sim 3 \mathrm{~min}$, and the vertical intervals are $50 \mathrm{~m}$ from the surface to $500 \mathrm{~m}$, $100 \mathrm{~m}$ to $2 \mathrm{~km}$, and $250 \mathrm{~m}$ to $10 \mathrm{~km}$ (Ware et al., 2013; Xu et al., 2014).

The MP-3000A unit observes brightness temperature at 35 channels, including $21 \mathrm{~K}$-bands $(22-30 \mathrm{GHz})$ and $14 \mathrm{~V}-$ bands $(51-59 \mathrm{GHz})$. Moreover, the MWR is equipped with an infrared radiation thermometer (IRT), which measures sky infrared temperature at one zenith infrared $(9.6-10.5 \mu \mathrm{m})$ channel and gives information on cloud-base temperature (Ware et al., 2013; Cimini et al., 2015; Xu et al., 2015). Meteorological sensors attached to the MWR can obtain ambient temperature, pressure, and relative humidity at the instrument level. The retrieval algorithm developed by the factory can automatically convert the microwave, infrared, and surface meteorological measurements into temperature, humidity, and liquid profiles with the aid of neural networks $(\mathrm{Xu}$ et al., 2015). Longtime radiosondes and liquid water content profiles generated from radiosondes were processed within a radiative transfer model and used as the neural network training set (Ware et al., 2013). A 5-year data set of historical radiosondes in Wuhan was used for neural network training (Xu et al., 2014).

Three snow cases (shown in Table 1) are selected to present the comparison of the profiles between MWR and RAOB under snow conditions, and the effect of off-zenith observation on improving the MWR measurement accuracy during snowfall is explored. All cases in this study include at least one RAOB profile during snowfall. Since it takes about $30 \mathrm{~min}$ for the balloon from the surface to $10 \mathrm{~km}$ height in sounding, the MWR retrievals were firstly averaged in a $\pm 15 \mathrm{~min}$ period centered at sounding times of 00:00 and 12:00 UTC and then compared with the RAOB profiles. Considering that the vertical resolution of the RAOB profiles is not consistent with that of MWR retrievals, the RAOB profiles should be interpolated to the height levels of the MWR retrievals. With the purpose of decreasing the smoothing error during interpolation, the RAOB profiles are firstly smoothed before interpolation with the kernel average smoothing method (Löhnert and Maier, 2012). Based on the above process, there are eight temporal pairs of MWR and RAOB profiles for comparison in this study. Methods used in this study are simply employed to calculate the correlation coefficients, bias (MWR observation minus RAOB), and root mean square error (RMSE) between the MWR and the RAOB for each parameter in zenith and off-zenith observations. The discrepancies between MWR retrievals and RAOB 
Table 1. Information of three snowfall cases used in this study.

\begin{tabular}{llr}
\hline Start time of snowfall & End time of snowfall & Cumulated snowfall (mm) \\
\hline 00:07 UTC on 5 Feb 2014 & 04:15 UTC on 7 Feb 2014 & 28.0 \\
07:16 UTC on 8 Feb 2014 & 04:22 UTC on 9 Feb 2014 & 2.3 \\
12:00 UTC on 17 Feb 2014 & 01:38 UTC on 18 Feb 2014 & 11.1 \\
\hline
\end{tabular}
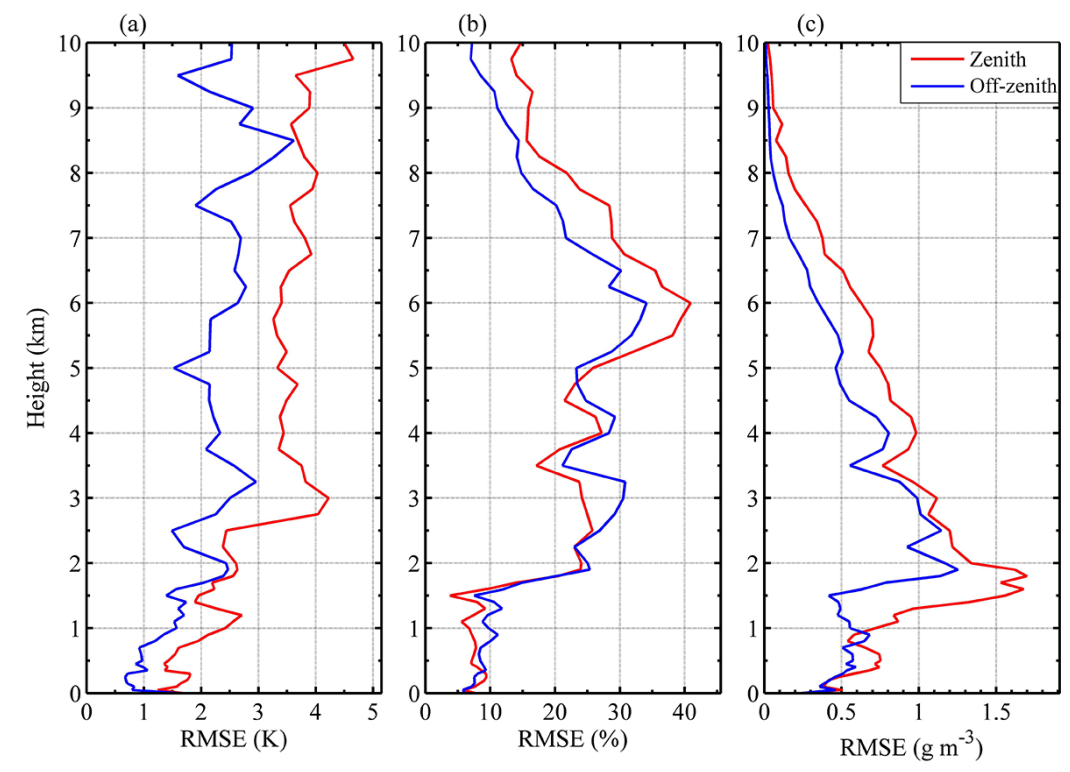

Figure 1. The comparison between zenith and off-zenith observations in non-precipitation conditions.

profiles at different heights are also calculated to explore how the MWR retrievals accuracies vary with height.

\section{Results analysis}

\subsection{Uncertainties of MWR retrievals in zenith and off-zenith observations under snow conditions}

To explore the effect of off-zenith observation on MWR measurement accuracy, the simultaneous MWR zenith and offzenith retrievals around the time of 00:00 and 12:00 UTC are compared with the RAOB profiles. Table 2 presents the comparison of MWR retrievals against RAOB profiles in zenith and off-zenith observations under snow conditions without considering the difference in altitude. All the MWR retrievals have a better correlation in off-zenith observations than in zenith observations especially for relative humidity, and the biases and RMSEs are also clearly reduced in off-zenith observations. For temperature, the MWR zenith observations have a warm bias of $4.6 \mathrm{~K}$ against RAOBs, while in off-zenith observations the bias decrease to $-0.6 \mathrm{~K}$, with RMSE also decreasing from 5.7 to $2.0 \mathrm{~K}$. The MWR-retrieved relative humidity has poor agreement with RAOB relative humidity in zenith observations but reasonable agreement in off-zenith observations, and the bias and RMSE also decrease from 10 and $33 \%$ in zenith observations to -2 and $20 \%$ in off-zenith observations, respectively. For vapor density, the correlation coefficient between MWR observations and RAOBs increases from 0.71 in zenith observations to 0.94 in off-zenith observations. In zenith observations, the bias is $1.43 \mathrm{~g} \mathrm{~m}^{-3}$ with a RMSE of $2.14 \mathrm{~g} \mathrm{~m}^{-3}$, while in off-zenith observations both of them decrease to $0.10 \mathrm{~g} \mathrm{~m}^{-3}$ and $0.66 \mathrm{~g} \mathrm{~m}^{-3}$, respectively. From these results we can affirm that the MWR retrievals have better accuracies against RAOBs in off-zenith observations than in zenith observations.

To further compare the uncertainties of MWR retrievals against RAOBs in zenith and off-zenith observations, the discrepancies between the MWR retrievals and the RAOB profiles at altitude under snow conditions are also investigated. Firstly, the comparison between zenith and off-zenith observation in non-precipitation conditions is shown in Fig. 1. To keep the comparison reasonable, we select 12 temporal pairs of MWR and RAOB profiles around the snow cases from 12:00 UTC on 2 February to 00:00 UTC on 5 February and from 12:00 UTC on 14 February to 00:00 UTC on 17 February in 2014 during non-precipitation. The variability of RMSEs is similar in zenith and off-zenith observations, and the value deviations between two observations are significantly smaller than those during snow conditions. Although the temperature RMSE in off-zenith observations is smaller 
Table 2. Comparison of MWR retrievals against RABOs in zenith and off-zenith observations under snow conditions when not considering the difference in altitude.

\begin{tabular}{llrrrr}
\hline Parameters & Observation mode & Temporal pairs & Correlation coefficient & Bias & RMSE \\
\hline \multirow{2}{*}{ Temperature } & Zenith & 8 & 0.93 & $5.2 \mathrm{~K}$ & $5.4 \mathrm{~K}$ \\
\multirow{3}{*}{ Relative Humidity } & Off-zenith & 8 & 0.99 & $0.1 \mathrm{~K}$ & $2.0 \mathrm{~K}$ \\
& Zenith & 8 & 0.31 & $8.4 \%$ & $32.2 \%$ \\
Vapor density & Off-zenith & 8 & 0.74 & $-4.2 \%$ & $22.1 \%$ \\
& Zenith & 8 & 0.72 & $1.51 \mathrm{~g} \mathrm{~m}^{-3}$ & $2.04 \mathrm{~g} \mathrm{~m}^{-3}$ \\
& Off-zenith & 8 & 0.95 & $0.17 \mathrm{~g} \mathrm{~m}^{-3}$ & $0.63 \mathrm{~g} \mathrm{~m}^{-3}$ \\
\hline
\end{tabular}
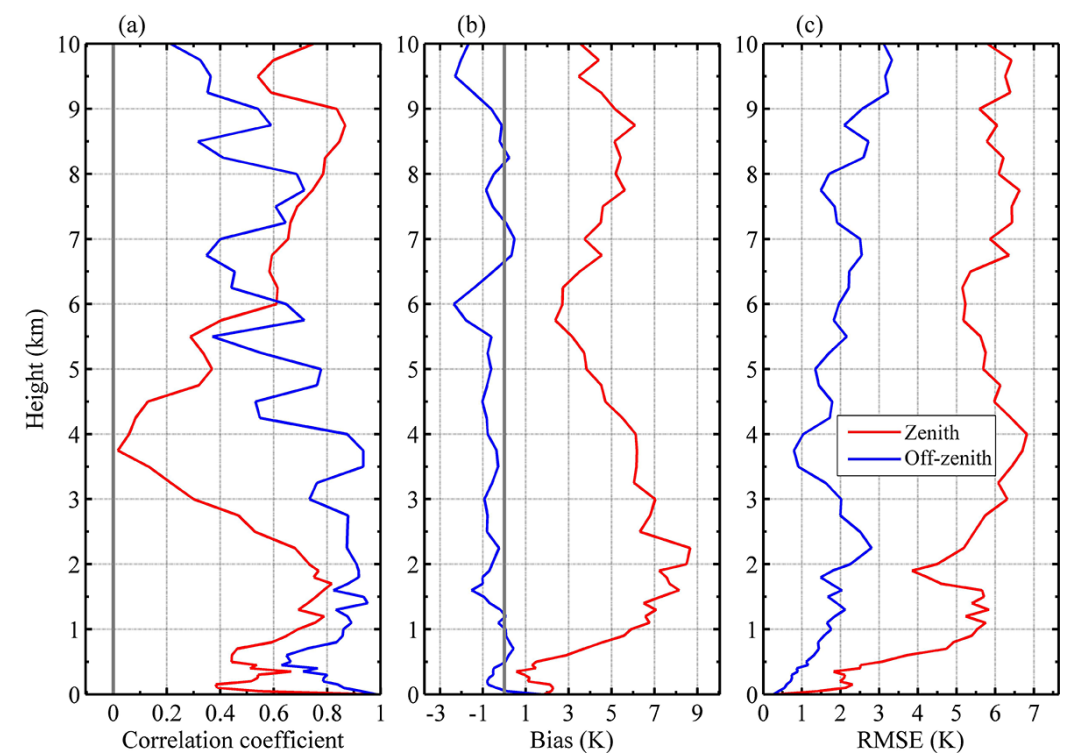

Figure 2. The correlation coefficient (a), bias (b), and RMSE (c) between the MWR and RAOB temperature in zenith (red) and off-zenith (blue) observations.

than that in zenith observations, the bias is less than $1 \mathrm{~K}$ at most heights. For relative humidity, and vapor density, RMSEs are not significantly different between zenith and offzenith observations. Those results demonstrate that there is no systematic bias in zenith observations, and the later comparison between zenith and off-zenith observations is reliable.

As shown in Fig. 2, the temperature correlation coefficients in zenith observations are smaller than those in offzenith observations below $6 \mathrm{~km}$, but the situation is opposite above $6 \mathrm{~km}$. The MWR temperature shows a warm bias against RAOB in zenith observations, and the bias is larger than $3 \mathrm{~K}$ at most heights, while in off-zenith observations the bias becomes cold and within $-1 \mathrm{~K}$ at most heights. Both the MWR temperature RMSEs in zenith and off-zenith observationss approximately increase with height, but the RMSE is clearly smaller in off-zenith observations. The MWR temperature RMSE is greater than $4 \mathrm{~K}$ above $0.5 \mathrm{~km}$ in zenith observations, while in off-zenith observations it is within $2 \mathrm{~K}$ at most heights.
Figure 3 presents the results for the relative humidity profiles. The correlation coefficients between MWR observations and RAOBs are negative at most heights below $2.5 \mathrm{~km}$. Compared with zenith observations, off-zenith observations have good agreement with RAOBs above $4.5 \mathrm{~km}$. In this study, the number of comparison samples is limited, and the relative humidity measured by RAOB is an integer. The relative humidity in the lower atmosphere is always lager than $95 \%$ during snowfall, so the relative humidity may remain constant at some heights for different RAOB measurements. In this case, the correlation coefficient cannot be calculated at those heights, so some breakpoints are shown in Fig. 3a. The biases of zenith and off-zenith observations are negative below $5 \mathrm{~km}$, and there are no distinct differences between them. Above $6 \mathrm{~km}$, the biases in both the zenith and off-zenith observations increase with height, but the bias is clearly smaller in off-zenith observations. It is the same situation for the RMSE; the RMSE differences between zenith and off-zenith observations are not evident below $5 \mathrm{~km}$, while above $5 \mathrm{~km}$ the RMSE is clearly smaller in off-zenith observations. 

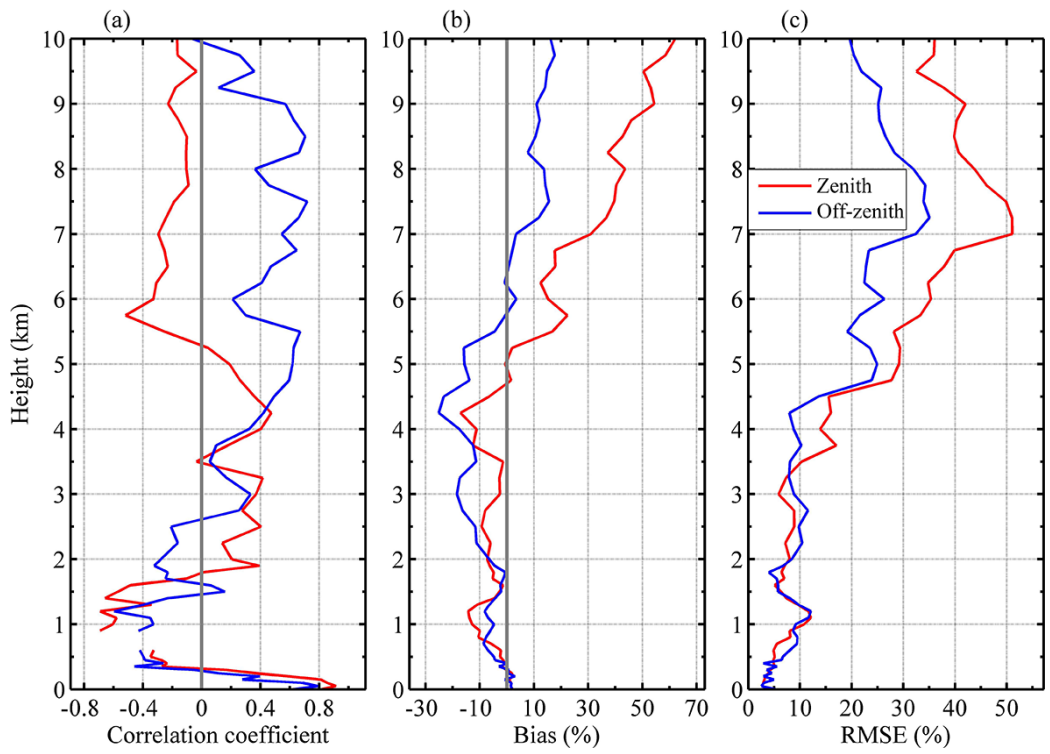

Figure 3. Same as Fig. 2 but for relative humidity profiles. Some breakpoints are shown in Fig. 3a because the compared RAOB relative humidity remains constant at these heights.
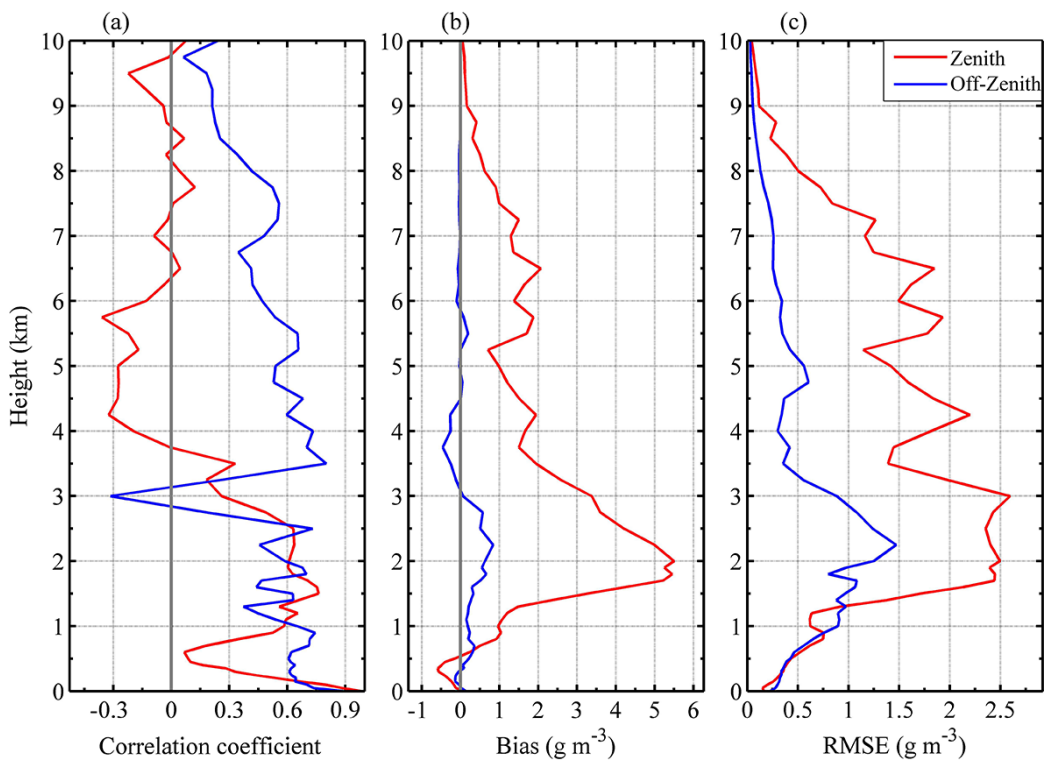

Figure 4. Same as Fig. 2 but for vapor density profiles.

The comparison results for the vapor density profiles are shown in Fig. 4. It can be seen that the correlation coefficient in zenith observations is positive below $3.5 \mathrm{~km}$ but mostly negative above $3.5 \mathrm{~km}$, while in off-zenith observations it is positive except around $3 \mathrm{~km}$. In general, the correlation coefficient is more reasonable in off-zenith observations than in zenith observations. The bias of vapor density in zenith observations increases from $0.13 \mathrm{~g} \mathrm{~m}^{-3}$ at surface to $5.51 \mathrm{~g} \mathrm{~m}^{-3}$ at $2 \mathrm{~km}$ and then decreases to $0.05 \mathrm{~g} \mathrm{~m}^{-3}$ at $10 \mathrm{~km}$ again, but in off-zenith observations the bias is clearly smaller with a value within $\pm 1.00 \mathrm{~g} \mathrm{~m}^{-3}$. Both the RM-
SEs in zenith and off-zenith observations vary similarly with height, whereby the RMSE in zenith (off-zenith) observations firstly increases to $3 \mathrm{~km}(2.3 \mathrm{~km})$ and then decreases to $0.04(0.03) \mathrm{g} \mathrm{m}^{-3}$ at $10 \mathrm{~km}$. Although the RMSE has a close value in zenith and off-zenith observations below $1.3 \mathrm{~km}$, it is clearly smaller in off-zenith observations above that height. The RMSE in zenith observations is mostly greater than $1.00 \mathrm{~g} \mathrm{~m}^{-3}$ with a peak of $2.60 \mathrm{~g} \mathrm{~m}^{-3}$, yet it is generally smaller than $1.00 \mathrm{~g} \mathrm{~m}^{-3}$ with a peak of $1.47 \mathrm{~g} \mathrm{~m}^{-3}$ in off-zenith observations. 

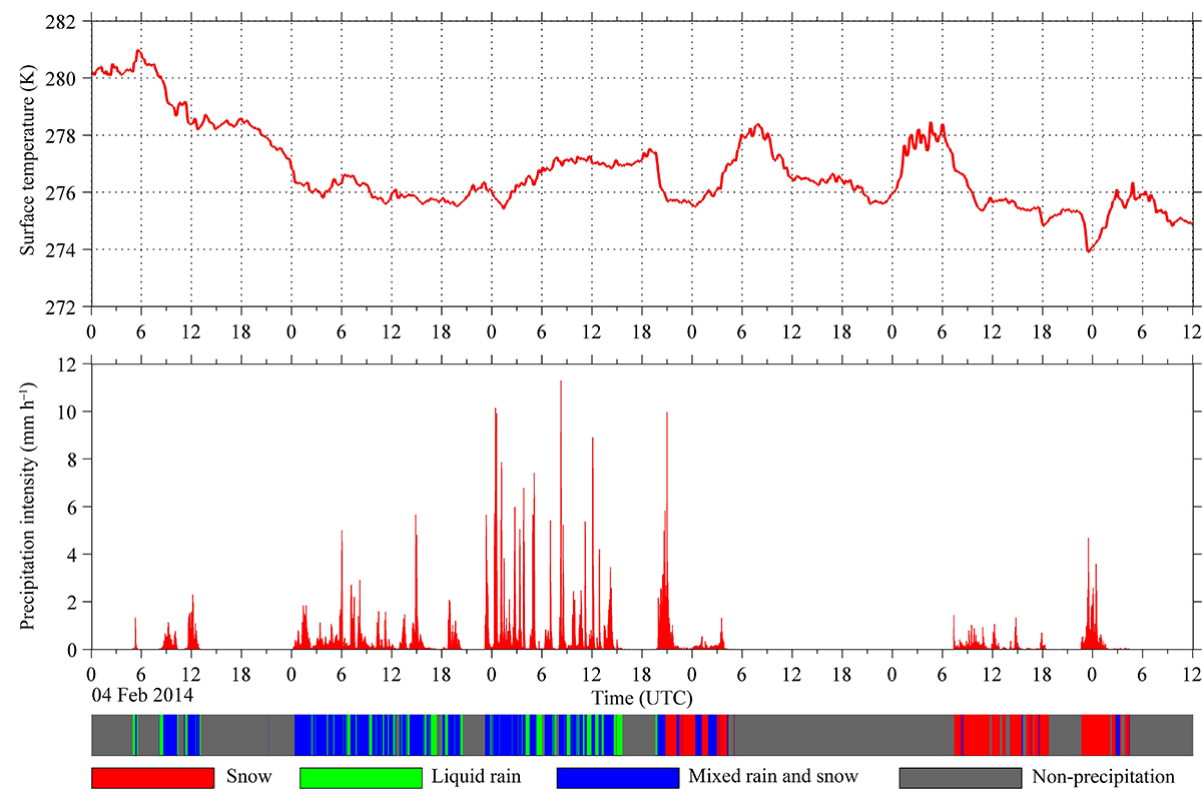

Figure 5. The time series of surface temperature measured by MWR, and precipitation intensity and precipitation type measured by the disdrometer from 00:00 UTC on 4 February 2014 to 12:00 UTC on 9 February 2014.

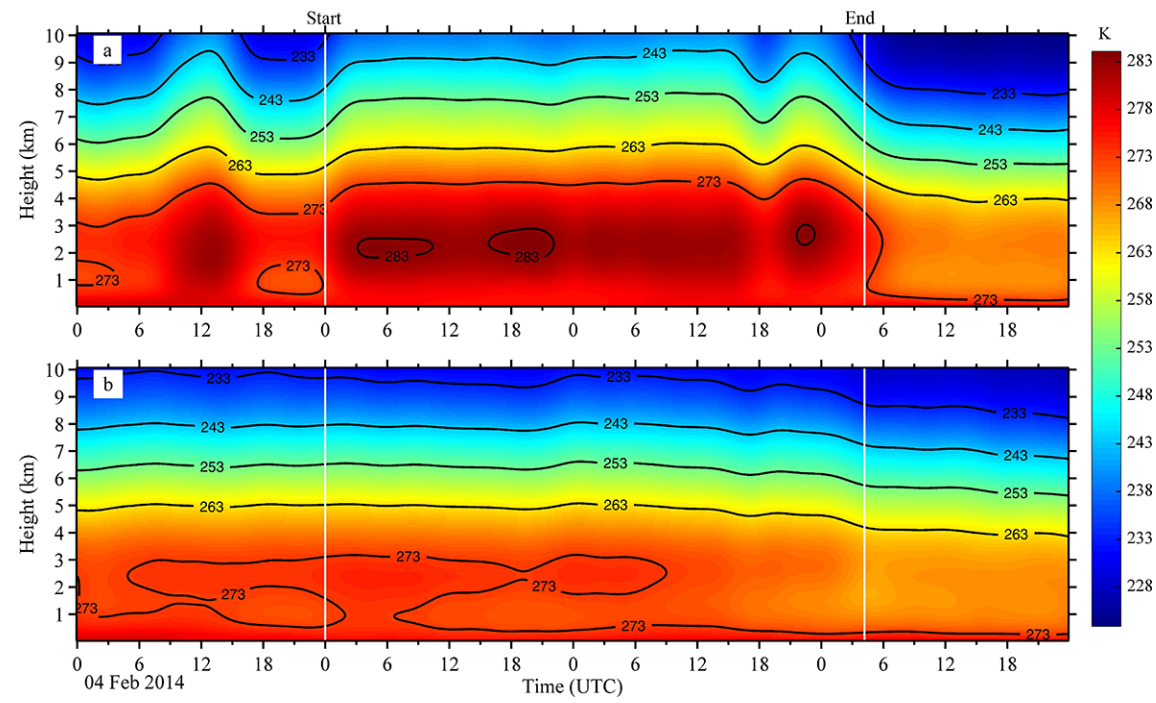

Figure 6. Comparison of temperature retrievals between zenith (a) and off-zenith (b) observation in heavy-snowfall conditions. The start and end times of snowfall are indicated by the vertical lines. The time series starts at 00:00 UTC on 4 February 2014.

Based on the above analysis, it is clear that snowfall has a significant impact on MWR measurement accuracy, and off-zenith observation can improve the accuracies of MWR retrievals under snow conditions, especially for the temperature and vapor density retrievals. Snowfall, as one form of precipitation, is not considered in the MWR retrieval algorithm method, so the MWR-retrieved atmospheric profiles in snow conditions are not as reasonable as those in nonprecipitation conditions (Xu et al., 2014). Although a special blower system is used to sweep water beads and snow away from the radome, snowfall, particularly heavy snowfall, will always freeze on the radome in a low-temperature situation. Snow produces a strong scattering signal in the microwave region, and the snow ice will increase signal noise of MWR measurement, so the frozen snow on the radome will have an influence on the MWR measurement of brightness temperature. Compared to zenith observation, off-zenith observation has better measurement accuracies under snow conditions. This is mainly because the MWR observes at $15^{\circ}$ elevation through vertical sections of the inverted U-shaped radome 


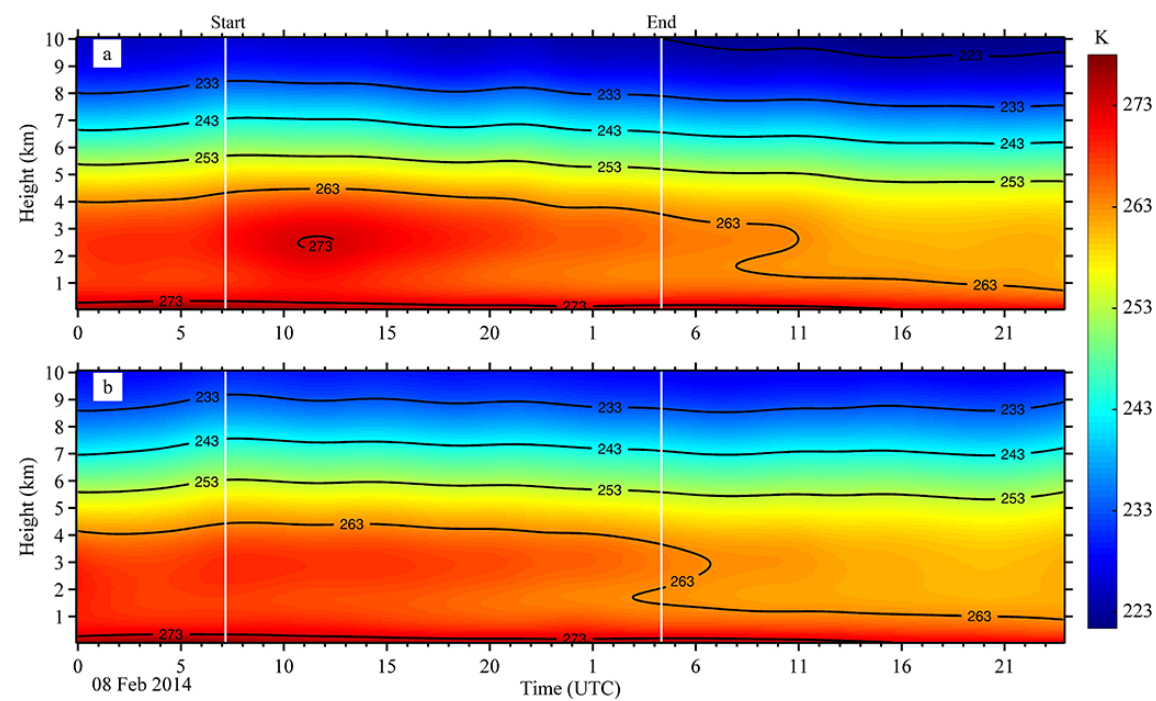

Figure 7. Comparison of temperature retrievals between zenith (a) and off-zenith (b) observation in light-snowfall condition. The start and end times of snowfall are indicated by the vertical lines. The time series starts at 00:00 UTC on 8 February 2014.

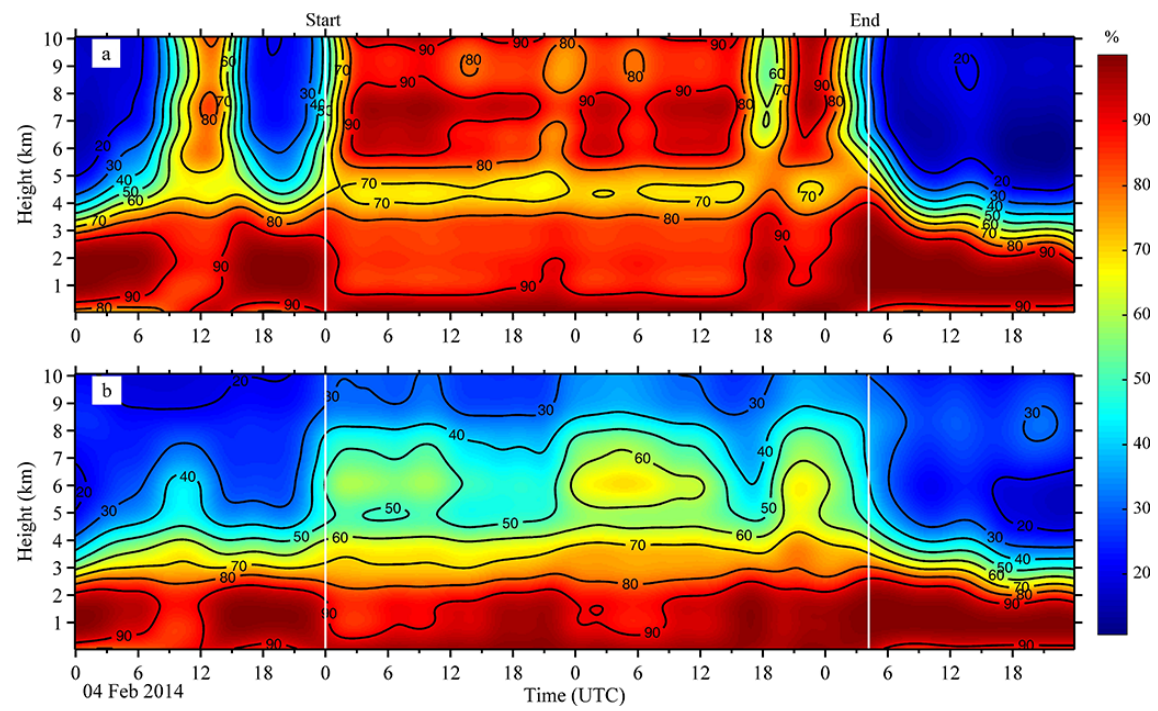

Figure 8. Same as Fig. 6 but for relative humidity retrievals.

that are more readily clear of snow/water droplets by gravity than the horizontal sections observed at zenith.

\subsection{Cases study}

To better understand the effect of off-zenith observation on the improvement of MWR retrieval accuracy, a comparison between the time series of the MWR retrievals during heavy snowfall and light snowfall is made. The heavy snowfall happens from 00:07 UTC on 5 February to 04:15 UTC on 7 February in 2014 with cumulative snowfall of $28.0 \mathrm{~mm}$, and the light snowfall happens from 07:16 UTC on 8 February to 04:22 UTC on 9 February in 2014 with cumulative snowfall of $2.3 \mathrm{~mm}$.
With the purpose of gaining a deep understanding of how precipitation affects the MWR measurement accuracy in this study, the time series of precipitation intensity, precipitation type, and surface temperature is described in Fig. 5. The precipitation intensity and type are measured by the disdrometer, and surface temperature is collected by the temperature sensor attached to the MWR. There are three precipitation events, from 05:00 to 13:00 UTC on 4 February, from 00:07 UTC on 5 February to 04:15 UTC on 7 February, and from 07:16 UTC on 8 February to 04:22 UTC on 9 February. The first two events are mainly mixed rain and snow, and the last one is snow, but, with the aid of the time variation of temperature and the measurements by the disdrometer, we 
can see that the first event is predominantly liquid rain and that the second event is mainly snow.

As shown in Fig. 6, the MWR-retrieved temperature in zenith observations presents a clear increase at $\sim 2.5 \mathrm{~km}$ in the heavy snowfall, but the increase is not clear in off-zenith observations. The MWR-retrieved temperature in zenith observations is about $10 \mathrm{~K}$ warmer than that in off-zenith observations when snowfall happens, and the warmer temperature corresponds well with the snowfall time. Before the snowfall event, there is also a warmer temperature from 05:00 to 15:00 UTC on 4 February, and this phenomenon may be caused by the rain at this time (Fig. 5). The warmer temperature disappeared in $1 \mathrm{~h}$ after the ending of heavy snowfall. Figure 7 illustrates the situation in light snowfall. The MWR temperature discrepancies between zenith and off-zenith observations are not as significant as those in heavy snowfall, and the MWR temperatures in zenith observations are about $3 \mathrm{~K}$ warmer than those in off-zenith observations at $\sim 2.5 \mathrm{~km}$ when snowfall happens.

The MWR-retrieved temperatures have good agreement between zenith and off-zenith observation in light-snow conditions, while they have poor agreement in heavy snowfall. As can be seen in Fig. 5, the precipitation type of heavy snowfall is mixed snow and rain, but the precipitation type is almost snow in the light-snowfall case. The liquid water and snow both can produce noise signals in the microwave region, but in different ways. The liquid water affects the MWR measurements with the emission, but the snow produces a scattering signal and a higher-frequency, larger scattering signal produced by snow (Kneifel et al., 2010). As we all know, the temperature profile is retrieved with a brightness temperature of 51-59 GHz. At these frequencies, the snow scattering is not significant, but the emission of liquid water is considerable. Furthermore, the precipitation intensity of light snow is obviously smaller than that in the heavysnow case, and the mixed snow and rain are more easily frozen on the radome than snow. Although a special blower system is used to sweep water beads and snow away from the radome, the heavy snowfall is hardly blown away and will easily freeze on the radome. Frozen snow will have an influence on the MWR measurement of brightness temperature, so the impact of snow on the MWR observations is clearer in heavy snowfall than in light snowfall. The warmer temperature in zenith observations is probably caused by the discrepancies of MWR-measured brightness temperature, and this will be helpful to explain why the warmer temperature is significant in heavy-snow conditions. Off-zenith observation significantly minimizes contamination from ice and snow, so the MWR-retrieved temperature in off-zenith observations is more reasonable especially in heavy snowfall. During lightsnow conditions, although the snow can be blown away by the special system, there will be snow left on the top of random that will convert to liquid water. The ice snow and liquid water also can produce noise signals and affect the MWR brightness temperature measurement in zenith observations.
So zenith observations also presented a $3 \mathrm{~K}$ warmer temperature than that in off-zenith observations.

The MWR relative humidity discrepancies in zenith and off-zenith observations are also significant in the heavy snowfall (Fig. 8). Although the MWR relative humidity presents good agreement in zenith and off-zenith observations below $2.5 \mathrm{~km}$, the MWR relative humidity retrievals in zenith observations are clearly larger than those in off-zenith observations above $5 \mathrm{~km}$ especially at $7 \mathrm{~km}$. The larger MWR relative humidity above $7 \mathrm{~km}$ in zenith observations is consistent with the timing of the heavy snowfall, while this situation is not so clear in the off-zenith observations. However, in light-snowfall conditions (Fig. 9), the discrepancies of relative humidity between zenith and off-zenith observations are not clear, and the variation with time is also more stable without the larger relative humidity above $6 \mathrm{~km}$ that appeared in heavy-snowfall conditions.

The situation for the vapor density is the same as the temperature. As shown in Fig. 10, the MWR vapor density retrievals in zenith observations are significantly larger than those in off-zenith observations at $\sim 2.5 \mathrm{~km}$ in the heavy snowfall, and the time of vapor density increasing is also consistent with the heavy-snowfall time. The heavy snowfall will also reduce the retrieval accuracies of vapor density by influencing the brightness temperature measurements of MWR; thus the trend of vapor density variation in zenith observations is similar to that of temperature in heavy snowfall. In off-zenith observations the MWR vapor density retrievals are more reasonable without the significant increments that appeared in zenith observations. In light snowfall (Fig. 11), the MWR vapor density retrievals present a similar trend in zenith and off-zenith observations, but the former is clearly larger than the latter below $3 \mathrm{~km}$.

Obviously, the MWR retrieval discrepancies between zenith and off-zenith observations are greater in heavy snowfall than in light snowfall. As mentioned before, this is mainly because snowfall is easier to freeze on the radome top in heavy snowfall and the noise signals caused by snowfall increase, while on the sides of the radome the snowfall drops to the ground by gravity, so the MWR retrieval discrepancies are greater in heavy snowfall, and the discrepancies can be reduced in off-zenith observations. Furthermore, as discussed by Kneifel et al. (2010), the measurements of brightness temperature will be affected by snow, and the depression is mainly caused by scattering of frozen hydrometeors. But the surface temperature at midlatitudes is not as low as that at high latitude and always higher than $0^{\circ}$, so the snow falling near surface will partially convert to liquid water, and the liquid water affects the MWR measurements with the emission of microwave, especially at high frequencies. In snowfall conditions, the scattering of upwelling radiation and changing of the surface reflections and emissivity may also result in enhancement of brightness temperature, but it is significant at frequencies above $90 \mathrm{GHz}$ (Kneifel et al., 2010). 


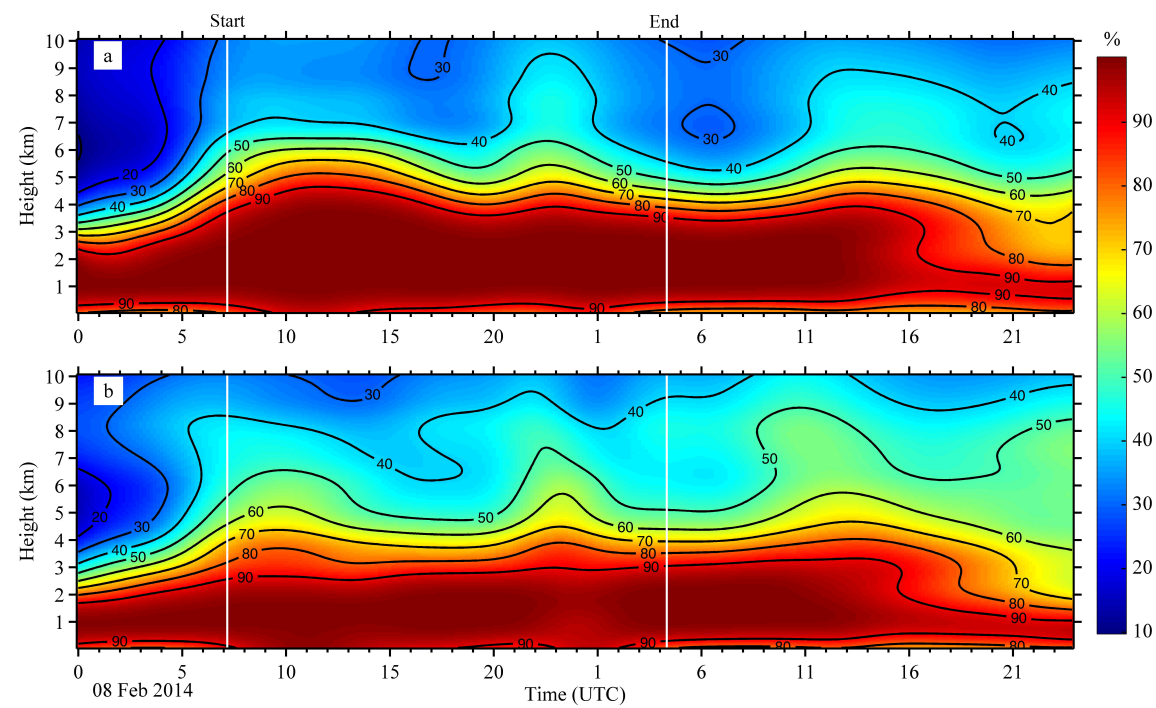

Figure 9. Same as Fig. 7 but for relative humidity retrievals.

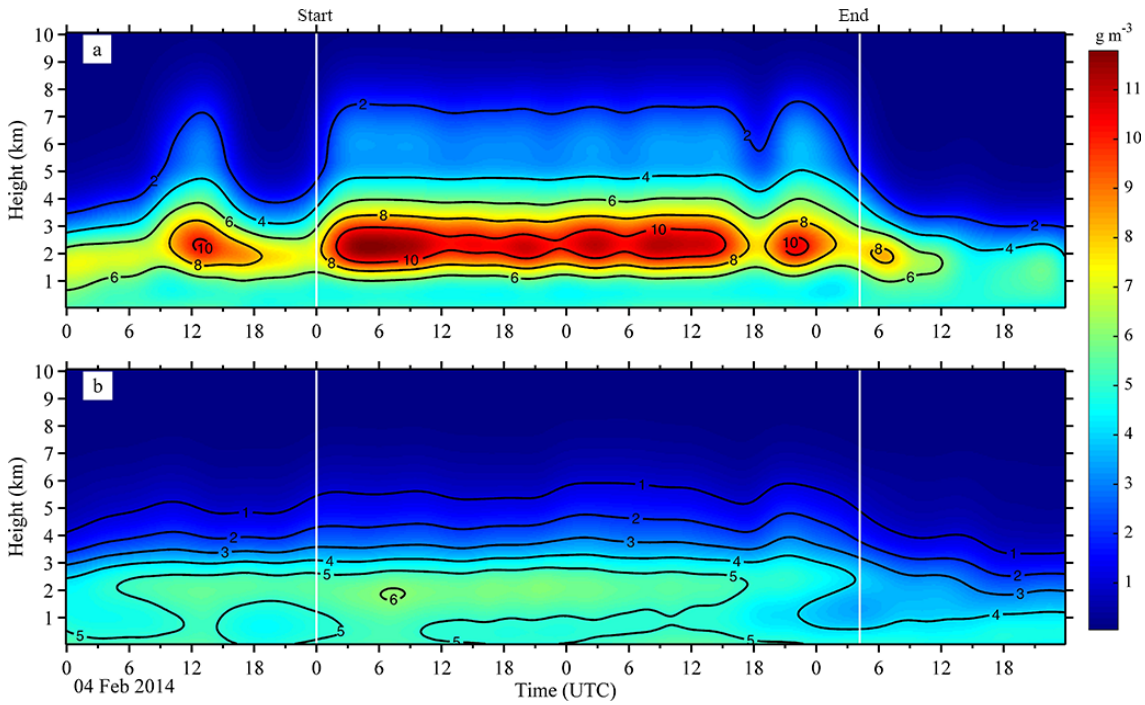

Figure 10. Same as Fig. 6 but for vapor density retrievals.

\section{Conclusions}

In this paper, the MWR retrieval accuracies in snow conditions are discussed by comparing them with the RAOBs, and the improvement of off-zenith observation in MWR measurements in snowfall is also investigated. We also present two snowfall cases to explore the impact of snowfall intensity on MWR retrieval accuracy. Based on the above analysis, we draw the following conclusions:

1. Without considering the difference in altitude, all MWR retrievals have a better correlation with RAOB profiles in off-zenith observations than in zenith observations especially for relative humidity when snowfall happens, and the biases and RMSEs are also clearly reduced in off-zenith observations. The temperature bias and RMSE decrease from 4.6 and $5.7 \mathrm{~K}$ in zenith observations to -0.6 and $2.0 \mathrm{~K}$ in off-zenith observations, respectively. The relative humidity bias and RMSE also decrease from 10 and $33 \%$ in zenith observations to -2 and $20 \%$ in off-zenith observations, respectively, and the correlation coefficient increases from 0.25 to 0.80 . For vapor density, the bias is $1.43 \mathrm{~g} \mathrm{~m}^{-3}$ with a RMSE of $2.14 \mathrm{~g} \mathrm{~m}^{-3}$ in zenith observations, while in off-zenith observations the bias decreases to $0.10 \mathrm{~g} \mathrm{~m}^{-3}$ with a smaller RMSE of $0.66 \mathrm{~g} \mathrm{~m}^{-3}$.

2. The discrepancies between MWR retrievals and RAOB profiles by altitude under snow conditions are also investigated. The MWR temperature shows a warm bias 


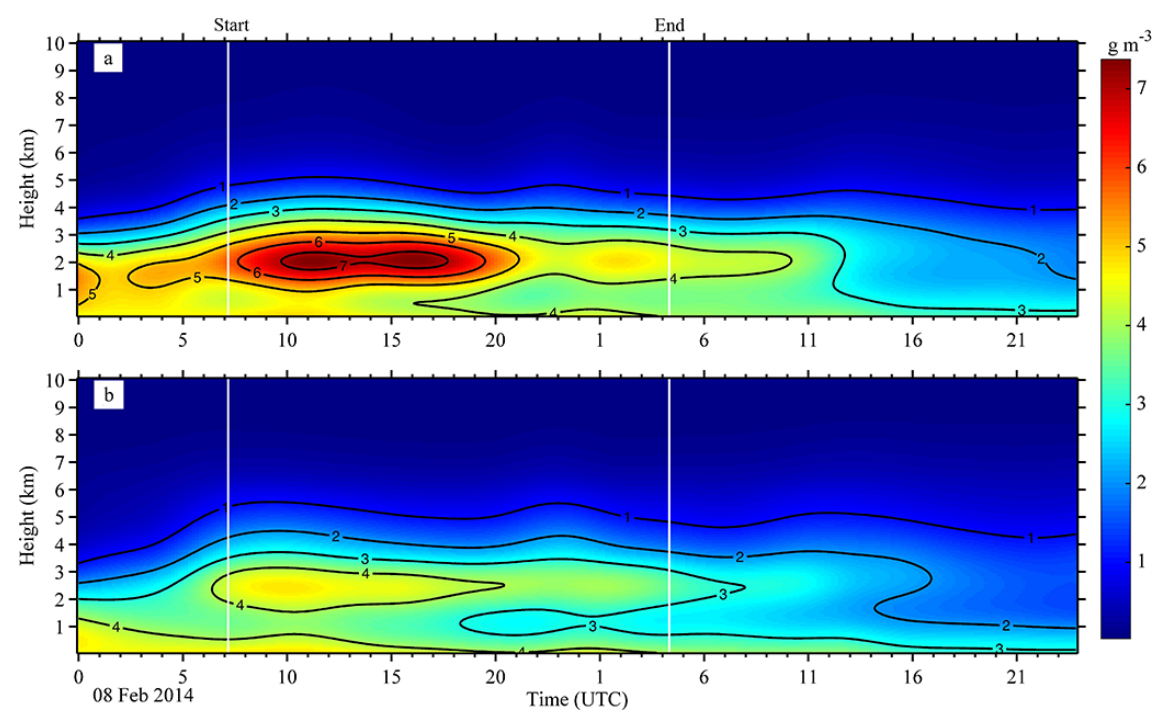

Figure 11. Same as Fig. 7 but for vapor density retrievals.

against RAOB in zenith observations, and the bias is larger than $3 \mathrm{~K}$ at most heights, while in off-zenith observations the bias becomes cold and is within $-1 \mathrm{~K}$ at most heights. The temperature RMSE is greater than $4 \mathrm{~K}$ above $0.5 \mathrm{~km}$ in zenith observations, while in offzenith observations it is within $2 \mathrm{~K}$ at most heights. The vapor density retrievals show the same situation: the bias and RMSE are clearly smaller in off-zenith observations than those in zenith observations at most heights. The off-zenith relative humidity retrievals show a better agreement with RAOBs above $4.5 \mathrm{~km}$, but the correlation coefficients are negative in zenith observations. Although the differences between zenith and offzenith observations in relative humidity bias and RMSE are insignificant below $5 \mathrm{~km}$, the bias and RMSE are clearly smaller in off-zenith observations above $6 \mathrm{~km}$.

3. Case studies show that heavy snowfall has an obvious impact on the accuracies of MWR retrievals by influencing MWR brightness temperature measurements, and off-zenith observation can mitigate the impact of snowfall. The MWR retrievals in zenith observations have an increasing trend during heavy-snowfall conditions, but the increase is weakened in off-zenith observations.

4. The poor MWR measurement accurate in snowfall is mainly due to the retrieval algorithm method, which does not consider the effect of snow. Moreover, the snowfall accumulating on the radome especially in heavy snowfall also increases the noise signal of MWR measurement. As the snowfall drops away by gravity on the sides of the radome, the off-zenith observations are more representative of the atmospheric conditions for RAOBs; thus off-zenith observation has a positive effect of mitigating the impact of snowfall.

\section{Data availability}

The data sets and accompanying MATLAB m-files used for the calculations in Table 2 and to plot all figures in this study are available at doi:10.5281/zenodo.235247 (Zhang, 2017).

Acknowledgements. This study was supported by the Hubei Meteorological Bureau project under grant 2014Q03; the open project of the Institute of Plateau Meteorology, CMA, Chengdu, under grant LPM2014009; the National Natural Science Foundation of China (NSFC) under grants 41620104009 and 41541037; and the National High Technology Research and Development Program (“863" Program) of China under grant 2012AA120902.

Edited by: D. Ruffieux

Reviewed by: two anonymous referees

\section{References}

Chan, P. W.: Performance and application of a multi-wavelength, ground-based microwave radiometer in intense convective weather, Meteorol. Z., 18, 253-265, doi:10.1127/09412948/2009/0375, 2009.

Chan, P. W. and Hon, K. K.: Performance of instability indices of the troposphere as derived from a ground-based microwave radiometer. The 11th Specialist Meeting on Microwave Radiometry and Remote Sensing of the Environment, Washington, DC, USA, 1-4 March 2010, 2010.

Cimini, D., Campos, E., Ware, R., Albers, S., Giuliani, G., Oreamuno, J., Joe, P., Koch, S. E., Cober, S., and Westwater, E.: Thermodynamic atmospheric profiling during 
the 2010 winter olympicsusingground-based microwave radiometry, IEEE T. Geosci. Remote, 49, 4959-4969, doi:10.1109/TGRS.2011.2154337, 2011.

Cimini, D., Nelson, M., Güldner, J., and Ware, R.: Forecast indices from a ground-based microwave radiometer for operational meteorology, Atmos. Meas. Tech., 8, 315-333, doi:10.5194/amt-8315-2015, 2015.

Kneifel, S., Löhnert, U., Battaglia, A., Crewell, S., and Siebler, D.: Snow scattering signals in ground-based passive microwave radiometer measurements, J. Geophys. Res., 115, D16214, doi:10.1029/2010JD013856, 2010.

Knupp, K. R., Ware, R., Cimini, D., Vandenberghe, F., Vivekanandan, J., Westwater, E., Coleman, T., and Phillips, D.: Ground-based passive microwave profiling during dynamic weather conditions, J. Atmos. Ocean. Tech., 26, 1057-1073, doi:10.1175/2008JTECHA1150.1, 2009.

Leena, P. P., Dani, K. K., Nath, A., Sanap, S. D., Pandithurai, G., and Kumar, V. A.: Validation of ground-based microwave radiometer data and its application in verifying atmospheric stability over Mahbubnagar during 2011 monsoon and post-monsoon seasons, Int. J. Remote. Sens., 36, 2920-2933, doi:10.1080/01431161.2015.1051632, 2015

Löhnert, U. and Maier, O.: Operational profiling of temperature using ground-based microwave radiometry at Payerne: prospects and challenges, Atmos. Meas. Tech., 5, 1121-1134, doi:10.5194/amt-5-1121-2012, 2012.

Löhnert, U., Kneifel, S., Battaglia, A., Hagen, M., Hirsch, L., and Crewell, S.: A multisensorapproach toward a better understanding of snowfall microphysics: the TOSCA project, B. Am. Meteorol. Soc., 92, 613-628, doi:10.1175/2010BAMS2909.1, 2011.

Madhulatha, A., Rajeevan, M., Ratnam, M. V., Bhate, J., and Naidu, C. V.: Nowcasting severe convective activity over southeast India using ground-based microwave radiometer observations, J. Geophys. Res., 118, 1-13, doi:10.1029/2012JD018174, 2013.

Marzano, F. S., Cimini, D., and Ware, R.: Monitoring of rainfall by ground-based passive microwave systems: models, measurements and applications, Adv. Geosci., 2, 259-265, doi:10.5194/adgeo-2-259-2005, 2005.
Matrosov, S. Y., Shupe, M. D., and Djalalova, I. V.: Snowfall retrievals using millimeter-wavelength cloud radars, J. Appl. Meteorol. Clim., 47, 769-777, doi:10.1175/2007JAMC1768.1, 2008.

Sánchez, J. L., Posada, R., García-Ortega, E., López, L., and Marcos, J. L.: A method to improve the accuracy of continuous measuring of vertical profiles of temperature and water vapor density by means of a ground-based microwave radiometer, Atmos. Res., 122, 43-54, doi:10.1016/j.atmosres.2012.10.024, 2013.

Ware, R., Cimini, D., Herzegh, P., Marzano, F., Vivekanandan, J., and Westwater, E.: Ground-based microwave radiometermeasurementsduring precipitation, The 8th Specialst Meeting on Microwave Radiometry, 24-27 February 2004, Rome, Italy, 2004.

Ware, R., Cimini, D., Campos, E., Giuliani, G., Albers, S., Nelson, M., Koch, S. E., Joe, P., and Cober, S.: Thermodynamic and liquid profiling during the 2010 Winter Olympics, Atmos. Res., 132-133, 278-290, doi:10.1016/j.atmosres.2013.05.019, 2013.

Xie, X. X., Löhnert, U., Kneifel, S., and Crewell, S.: Snow particle orientation observed by ground-based microwave radiometry, J. Geophys. Res., 117, D02206, doi:10.1029/2011JD016369, 2012.

Xu, G. R., Ware, R., Zhang, W. G., Feng, G. L., Liao, K. W., and Liu, Y. B.: Effect of off-zenith observations on reducing the impact of precipitation on ground-based microwave radiometer measurement accuracy, Atmos. Res., 140-141, 85-94, doi:10.1016/j.atmosres.2014.01.021, 2014.

Xu, G. R., Xi, B. K., Zhang, W. G., Cui, C. G., Dong, X. Q., Liu, Y. B., and Yan, G. P.: Comparison of atmospheric profiles between microwave radiometer retrievals and radiosonde soundings, J. Geophys. Res.-Atmos., 120, 1031310323, doi:10.1002/2015JD023438, 2015.

Zhang, W.: AMT-2016-253-DATA SETS [Data set], Zenodo, doi:10.5281/zenodo.235247, 2017. 